This item was submitted to Loughborough's Research Repository by the author.

Items in Figshare are protected by copyright, with all rights reserved, unless otherwise indicated.

\title{
Investigation into suitability of current ATDs to represent ageing drivers
}

PLEASE CITE THE PUBLISHED VERSION

http://dx.doi.org/10.1080/13588265.2012.730211

PUBLISHER

(c) Taylor and Francis

VERSION

AM (Accepted Manuscript)

LICENCE

CC BY-NC-ND 4.0

REPOSITORY RECORD

Acar, B. Serpil, J. Feng, and Volkan Esat. 2019. "Investigation into Suitability of Current Atds to Represent Ageing Drivers". figshare. https://hdl.handle.net/2134/14954. 


\title{
Investigation into suitability of current ATDs to represent ageing drivers
}

\author{
B. Serpil Acar ${ }^{\mathrm{a} *}$, J. Feng ${ }^{\mathrm{b}}$ and V. Esat ${ }^{\mathrm{C}}$ \\ ${ }^{a}$ Design School, Loughborough University, Loughborough, UK; ${ }^{b}$ School of Engineering, Manchester Metropolitan University, \\ Manchester, UK; ${ }^{c}$ Mechanical Engineering Program, Middle East Technical University - Northern \\ Cyprus Campus, Guzelyurt, Mersin, Turkey
}

\begin{abstract}
Ageing car occupants are expected to become a larger part of the driver and passenger population in developed countries in the future. Currently, Anthropomorphic Test Devices (ATDs) are essential tools to assess safety of automobiles; however, they do not fully embody the features of all occupant groups in the world population. This study investigates the features of ageing drivers. The data are collected and analysed with respect to age and gender. Information particularly on driver-automobile interaction is provided in the form of distances and angles measured in-car. The physical characteristics of existing ATDs are investigated and compared with the anthropometric data of ageing drivers. Comparisons indicate that the current ATDs do not incorporate some of the features of ageing drivers. The requirements of future ATDs such as sitting height, abdominal depth and posture are discussed. These specifications are essential for the development of new ATDs representing ageing drivers.
\end{abstract}

Keywords: ageing; ageing driver; anthropometric measurements; in-car measurements; ATD

\section{Introduction}

The increasing proportion of older drivers in western countries and accident patterns involving older occupants are serious concerns in the automotive safety field. In many OECD (Organization for Economic Cooperation and Development) countries, by the year 2030, 25\% will be aged 65 or over [13]. Figure 1 shows the population distribution by age in the United Kingdom. It shows the increase in ageing populations over the past 20 years and the predictions for the future 20 years. The population over 60 years old is projected to increase from $20.8 \%$ in 1988 to $27.6 \%$ in 2028 [14].

In western countries, most of the physically and mentally able older drivers travel in their own cars [17]. This suggests that there will be many more older drivers on roads in the future. Figure 2 shows that older drivers drive fewer miles than their younger counterparts, whereas in Figure 3 'fatalities per mile driven' data indicate that the drivers of this age group have the greatest risk of being involved in a fatal crash [2,3].

The research on car crash patterns indicates that older drivers are more likely to be involved in intersection crashes and side impact crashes [10]. Analysis of the UK in-depth accident data reveals that the older car occupants are significantly more prone to serious chest injuries than their younger counterparts [17].

Physical human models have been generated to be used in crash test laboratories. The most commonly used physical
Anthropomorphic Test Device (ATD) for frontal impacts is the Hybrid III 50th percentile male model. Hybrid III 5th percentile female and 95th percentile male are also used to assess biomechanical behaviour of small and large occupants, respectively. The side impact ATDs such as World- SID 50th, Bio-SID, ES-2 and US DOT SID represent 50th percentile male population. SID-IIs and WorldSID 5th are used to represent small occupants in side crash tests. The current ATDs used in rear crash tests, namely, BioRID II and RID3D, only represent the average male.

At present, a dummy, which is particularly designed to represent ageing car occupants, is not available. The aim of this paper is to investigate the suitability of current ATDs to represent the ageing car occupants.

\section{Features of ageing automobile occupants}

The measurements techniques and methodology used are verified in [7]. Loughborough University (LU) Ethical Advisory Committee approval is granted before the experiments started. The anthropometric measurements and in-car measurements - reflecting the driving posture - are taken from 100 volunteers aged 65 years and older, of which 54 are female, and 46 are male.

\section{Data collection}

Instruments used in this study comprise of an anthropometer, rulers, a scale and height measuring tools. The standard 


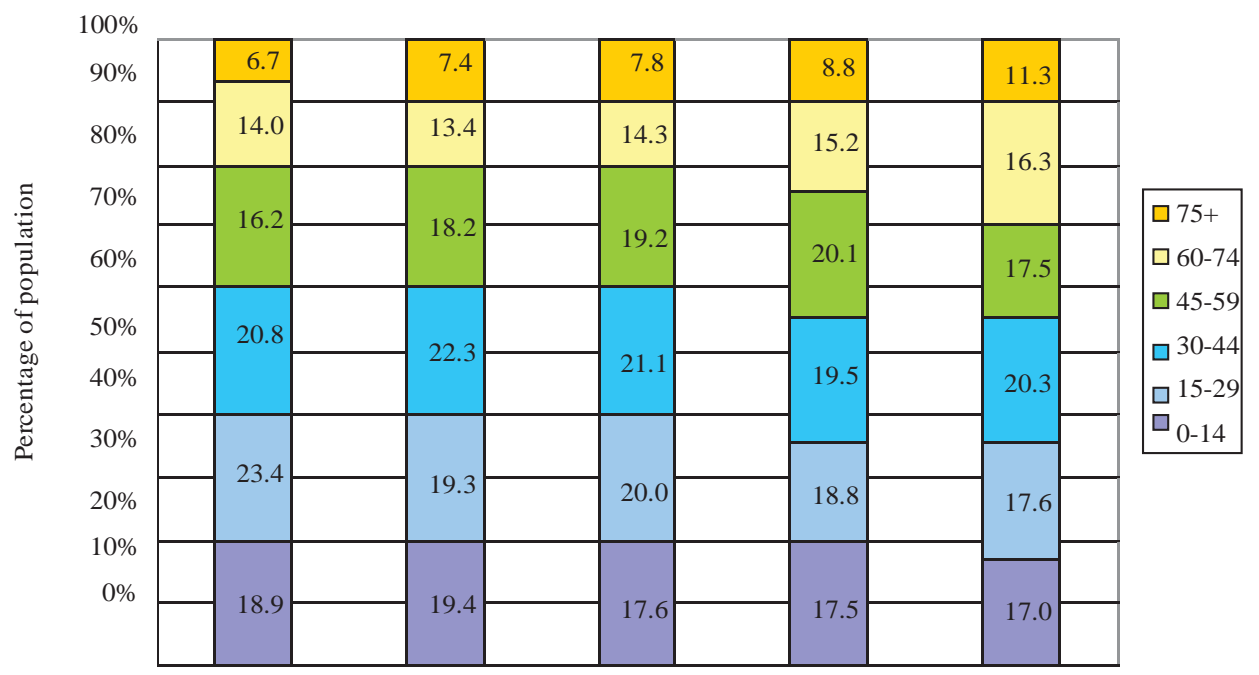

Figure 1. Past and projected population by age in the United Kingdom, 1988-2028 [14].

anthropometric measurements and the corresponding definitions of parameters are based on the Older Adult Data [15]. The sample anthropometric measurements presented in this study are illustrated in Figure 4. The incar measurements are collected in a typical driving position as shown in Figure 5. Two sets of parameters, i.e.: (1) the distance between the joints, and (2) the distance between the body and the car parts are measured in car.
Figure 6 exhibits a typical set of in-car measurements in the experiment and their definitions in the key tables. During measurements, the volunteers are required to take off their coats to assist in identifying the location and the axis of rotation of the joints. Six joints are labelled with anatomical landmarks (acromion, lateral epicondyle, ulnar styloid, great trochanter, lateral condyle and lateral malleolus) as depicted in Figures 5-7.

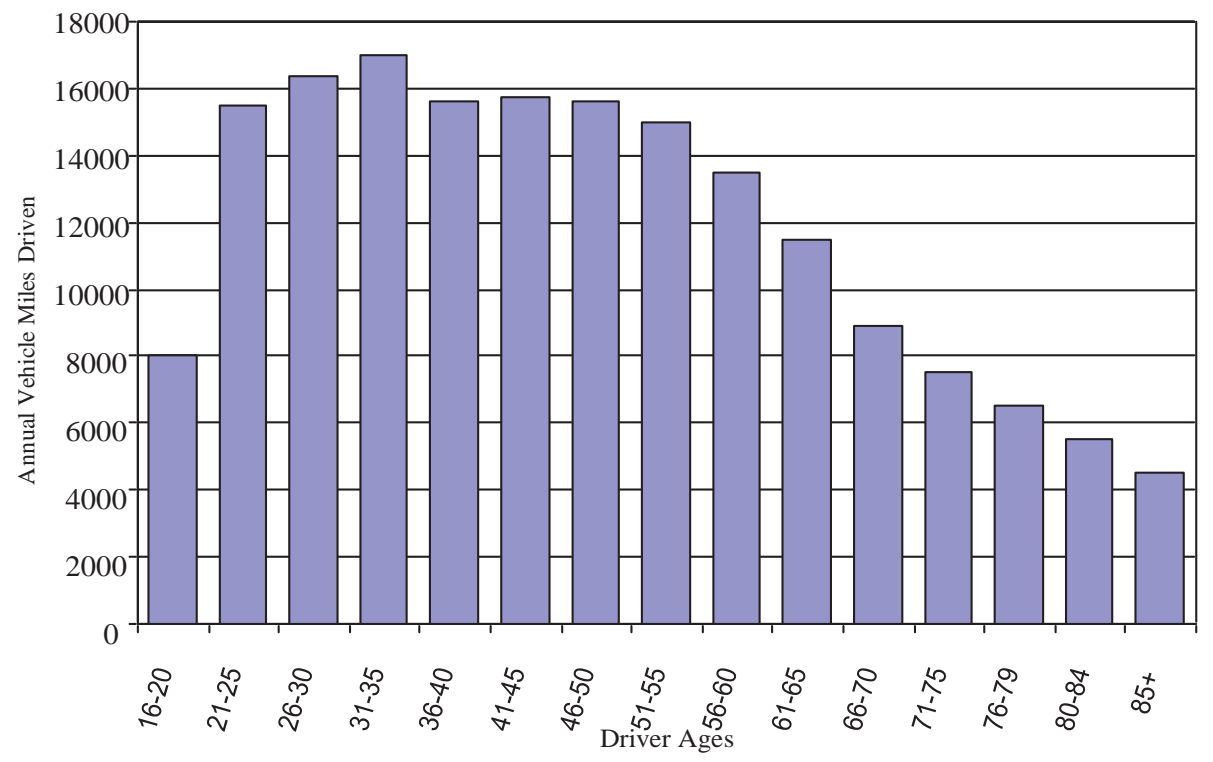

Figure 2. Annual miles driven vs. driver age in the USA [3]. 


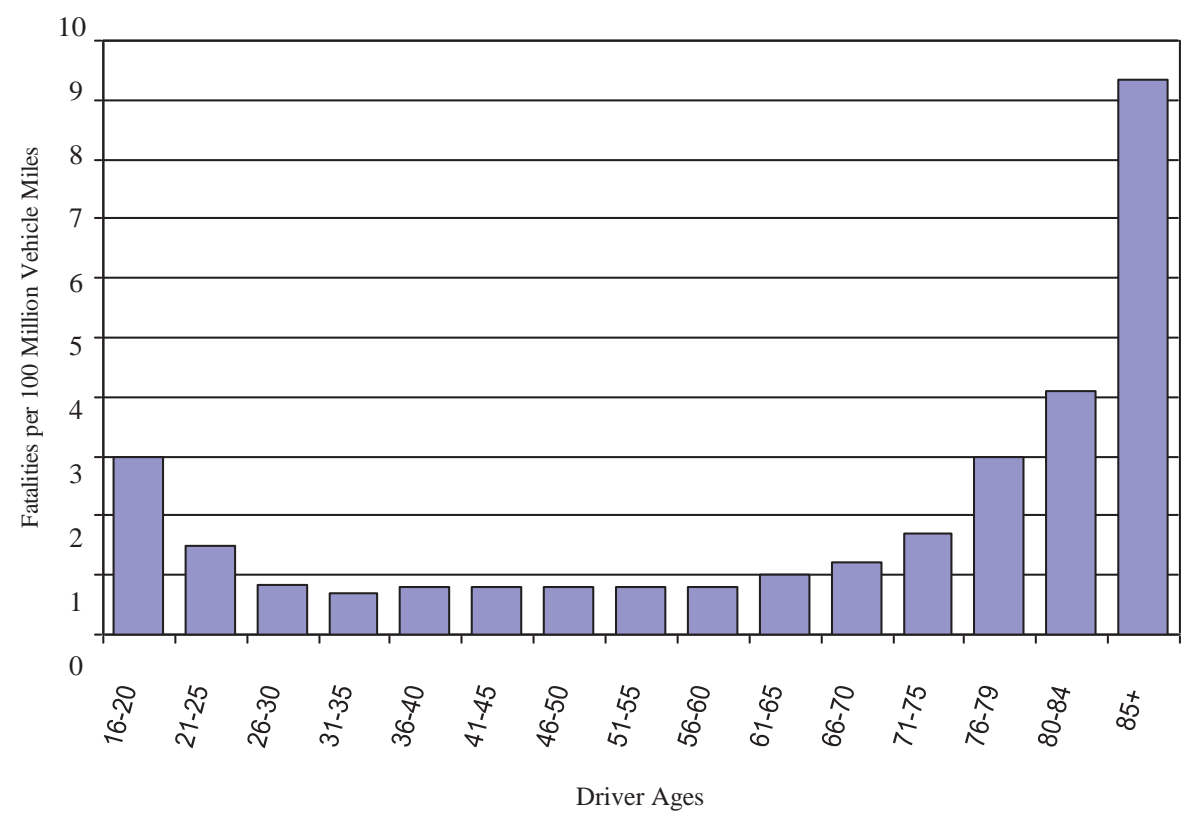

Figure 3. Fatalities per vehicle miles vs. driver age in the USA [2].
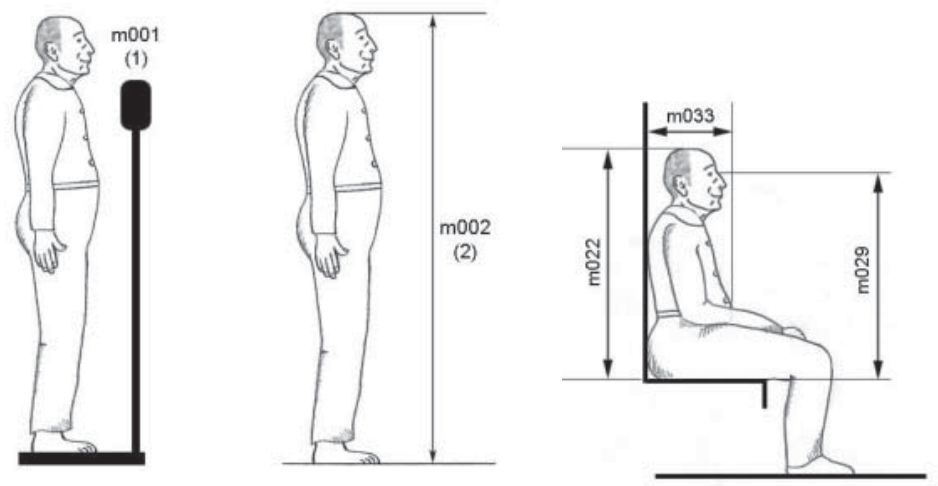

\begin{tabular}{ll}
\hline ID-No & Measurement definitions \\
\hline m001 & weight \\
m002 & height \\
m022 & sitting height \\
m029 & eye height \\
m052 & abdominal depth \\
\hline
\end{tabular}

Figure 4. Sample anthropometric measurements.

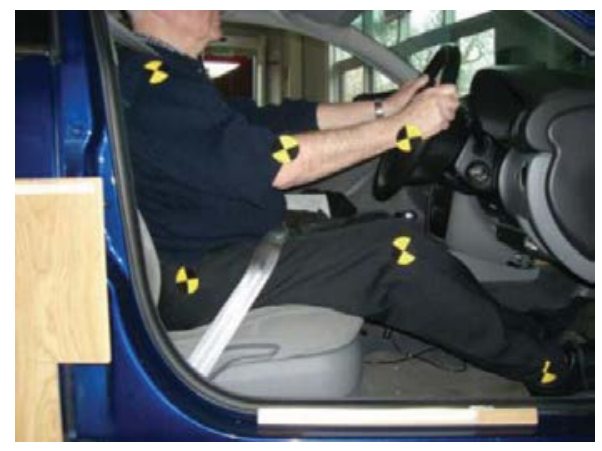

Figure 5. An ageing volunteer in driver position.

Photographs are also taken for data confirmation, angle calculations and as a backup for the measurements. The distance between the joints and the distance between the body and the car parts are compared with the distances measured from the photographs. A good match for the distances is achieved. The angles between the lines joining the joints and the horizontal are extracted from the photographs (Figure 7(a)). Some of the angles between the lines joining the joints are derived from the geometry relationship of angles. As an example, m070 = m065 - m066. The aforementioned angles are shown in Figure 7(b). Videos are also recorded for observation as volunteers get in and out of the car and as they put on and take off their seat belts.

The data collected are analysed with respect to gender and age. Statistical significance is determined through Student's $t$-Test, the confidence level of which is assumed to be the associated probability ( $p$ ) value of 0.05 . The Student's $t$ Test results are mentioned only when statistical significance is achieved. 


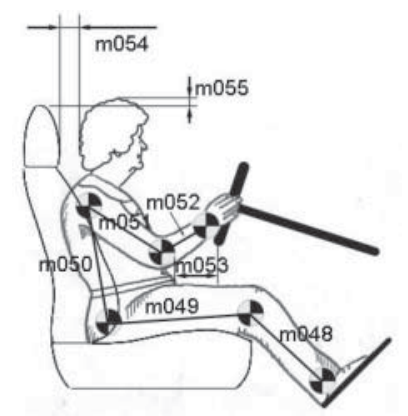

\begin{tabular}{ccl}
\hline ID-No & \multicolumn{1}{c}{ Measurement definitions } \\
\hline m048 & \multicolumn{1}{c}{$\begin{array}{l}\text { ankle-knee } \\
\text { knee-hip }\end{array}$} \\
m049 & $\begin{array}{l}\text { Distance between } \\
\text { h050 }\end{array}$ & shoints \\
m051 & & $\begin{array}{l}\text { shoulder-elbow } \\
\text { elbow-wrist }\end{array}$ \\
m052 & & Torso-Steering Wheel \\
m053 & Distance between & Backset: back of head-head restraint \\
m054 & human body and car & Top of the Head-top of head restraint \\
m055 & components &
\end{tabular}

Figure 6. In-car distance measurements.

\section{Comparison of the anthropometric measurements}

Weight, stature and sitting height are important parameters with regard to driving position and accident investigation. Ageing data are compared with the corresponding data for the younger adult females and males (aged 18-64) found from literature [15] as shown in Table 1. In Table 2, comparison between the age groups 65-69 and 70+ is conducted within the LU data for both genders. In both tables, the differences between the parameters are calculated through the formula below:

$\%$ Difference $=[(P$ younger $-P$ older $) / P$ younger $] \times 100$

where Pyounger is the corresponding parameter for the younger female and males (aged 18-64 in Table 1 and 65-69 in Table 2) and Polder is the parameter for the older female and males (aged 65+ in Table 1 and 70+ in Table 2) in this study. Negative sign in the difference row indicates younger data being smaller than the older data.
Table 1 reveals that the ageing occupants are heavier than the younger adults on average, reaching to an almost 8.5\% difference for 5th percentile females, and 95th per- centile males and almost $9 \%$ difference for 50th percentile males. The mean height of ageing and young adult groups is similar, however, sitting height data show that the ageing people form an almost $8 \%$ shorter group than the younger adults. For 5 th percentile females and 95 th percentile males the difference is even greater, above $10 \%$ for both cases. Therefore, sitting height appears to be a critical dimension, which is of high importance in terms of occupant safety.

Table 2 helps to understand if there are any differences between the relatively younger and older ageing population within LU measurements. The data are classified into two groups: for females, 25 volunteers form 65-69 age group, whereas 29 form 70+ age group; for males, 16 volunteers (a)

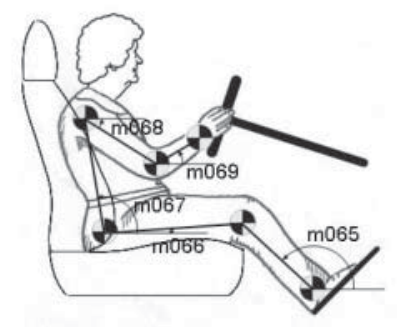

(b)

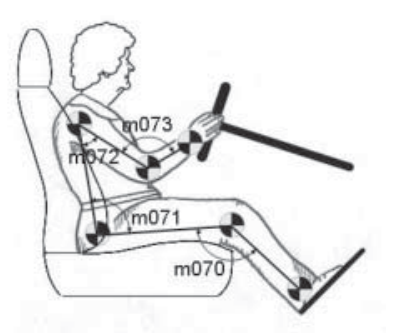

\begin{tabular}{|c|c|c|}
\hline ID-No & \multicolumn{2}{|c|}{ Measurement definitions } \\
\hline m065 & \multirow{5}{*}{$\begin{array}{l}\text { Angles between the } \\
\text { lines joining the joints } \\
\text { w.r.t. horizontal }\end{array}$} & ankle-knee \\
\hline m066 & & knee-hip \\
\hline m067 & & hip-shoulder \\
\hline m068 & & shoulder-elbow \\
\hline m069 & & elbow-wrist \\
\hline $\mathrm{m} 070$ & \multirow{4}{*}{$\begin{array}{l}\text { Angles between the lines } \\
\text { joining the joints }\end{array}$} & ankle-knee-hip \\
\hline m071 & & knee-hip-shoulder \\
\hline m072 & & hip-shoulder-elbow \\
\hline $\mathrm{m} 073$ & & shoulder-elbow-wrist \\
\hline
\end{tabular}

Figure 7. In-car angle measurements: (a) angles between the lines joining the joints with respect to horizontal; (b) angles between the lines joining the joints. 
Table 1. Comparison of the selected anthropometric dimensions between younger and ageing adults.

\begin{tabular}{|c|c|c|c|c|c|}
\hline \multirow[b]{2}{*}{ Measurement definitions } & \multirow[b]{2}{*}{ Age } & \multicolumn{2}{|c|}{ Female $(n=54)$} & \multicolumn{2}{|c|}{ Male $(n=46)$} \\
\hline & & Mean (SD) & 5th percentileMean (SD) & & \\
\hline \multirow[t]{3}{*}{ Weight (kg) } & $65+$ & $68.5(12.3)$ & 48.8 & $86.7(14.4)$ & 115 \\
\hline & $18-64$ & $66.7(13.2)$ & 45.0 & $79.8(13.0)$ & 106 \\
\hline & \% Difference & $-2.70 \%$ & $-8.44 \%$ & $-8.71 \%$ & $-8.49 \%$ \\
\hline Stature (mm) & $\begin{array}{c}65+ \\
18-64 \\
\text { \% Difference }\end{array}$ & $\begin{array}{c}1587(58) \\
1620(64) \\
2.04 \%\end{array}$ & $\begin{array}{c}1486 \\
1514 \\
1.85 \%\end{array}$ & $\begin{array}{c}1749(64) \\
1755(70) \\
0.34 \%\end{array}$ & $\begin{array}{c}1845 \\
1955 \\
5.63 \%\end{array}$ \\
\hline Sitting height (mm) & $\begin{array}{c}65+ \\
18-64 \\
\text { \% Difference }\end{array}$ & $\begin{array}{c}791(37) \\
858(33) \\
7.81 \%\end{array}$ & $\begin{array}{c}721 \\
803 \\
10.21 \%\end{array}$ & $\begin{array}{c}849(42) \\
920(36) \\
7.72 \%\end{array}$ & $\begin{array}{c}903 \\
1008 \\
10.42 \%\end{array}$ \\
\hline
\end{tabular}

Table 2. Comparison of the selected anthropometric dimensions between age groups within LU data.

\begin{tabular}{|c|c|c|c|c|c|}
\hline \multirow[b]{2}{*}{ Measurement definitions (mm) } & \multirow[b]{2}{*}{ Age } & \multicolumn{2}{|c|}{ Female } & \multicolumn{2}{|c|}{ Male } \\
\hline & & Mean (SD) & 5th percentile & Mean (SD) & 95th percentile \\
\hline \multirow[t]{2}{*}{ Sitting height } & $65-69$ & $798(35)$ & 753 & $860(56)$ & 915 \\
\hline & $\begin{array}{c}70+ \\
\text { \% Difference } \\
\text { 65-69 }\end{array}$ & $\begin{array}{c}782(39) \\
2.01 \% \\
685(32)\end{array}$ & $\begin{array}{c}709 \\
5.84 \% \\
637\end{array}$ & $\begin{array}{c}845(33) \\
1.74 \% \\
743(55)\end{array}$ & $\begin{array}{c}901 \\
1.53 \% \\
802\end{array}$ \\
\hline Eye height (sitting) & $\begin{array}{c}70+ \\
\text { \% Difference } \\
\text { 65-69 }\end{array}$ & $\begin{array}{c}678(33) \\
1.02 \% \\
317(43)\end{array}$ & $\begin{array}{c}623 \\
2.20 \% \\
249\end{array}$ & $\begin{array}{c}727(29) \\
2.15 \% \\
351(54)\end{array}$ & $\begin{array}{c}768 \\
4.24 \% \\
441\end{array}$ \\
\hline \multirow{2}{*}{ Abdominal depth } & $70+$ & $342(46)$ & 277 & $354(46)$ & 456 \\
\hline & \% Difference & $-7.89 \%$ & $-11.25 \%$ & $-0.85 \%$ & $-3.40 \%$ \\
\hline
\end{tabular}

constitute 65-69 age group, and the 70+ age group include 30 people. It is shown in Table 2 that the sitting height and eye height (in sitting position) of older subjects $(70+)$ are slightly lower than those of younger ageing (65-69) subjects. The abdominal depths of both age groups have very close mean values for males, however, the difference is somewhat greater for females, reaching to around $8 \%$ for mean values and around $11 \%$ for the 5th females, indicating greater abdominal depths for relatively older occupants. These results indicate that there are no notable differences between the younger and older ageing populations, i.e. as ageing progresses further in the ageing population, occupants appear to get slightly shorter with a lower range of vision and a greater abdominal depth, however, these differences are not statistically significant.

\section{Comparison of the in-car measurements}

The in-car measurements of ageing occupants in this study are classified into three groups: distances between joints (Table 3), angles between joints (Table 4) and distances between human body and automobile features (Table 5). The measurements in the tables are only a set of samples among the total of 73 different measurements taken.

Table 3. Comparison of the distances between joints measured in-car.

\begin{tabular}{|c|c|c|c|c|c|}
\hline \multirow[b]{2}{*}{ Measurement definitions (mm) } & \multirow[b]{2}{*}{ Age } & \multicolumn{2}{|c|}{ Female } & \multicolumn{2}{|c|}{ Male } \\
\hline & & Mean (SD) & 5th percentile & Mean (SD) & 95th percentile \\
\hline Ankle-knee & $65-69$ & $367(26)$ & 322 & $422(20)$ & 451 \\
\hline Knee-hip & $\begin{array}{c}70+ \\
65-69\end{array}$ & $\begin{array}{l}368(30) \\
429(23)\end{array}$ & $\begin{array}{l}323 \\
398\end{array}$ & $\begin{array}{l}412(24) \\
453(27)\end{array}$ & $\begin{array}{l}441 \\
478\end{array}$ \\
\hline Hip-shoulder & $\begin{array}{c}70+ \\
65-69\end{array}$ & $\begin{array}{l}423(33) \\
381(25)\end{array}$ & $\begin{array}{l}373 \\
353\end{array}$ & $\begin{array}{l}450(31) \\
412(34)\end{array}$ & $\begin{array}{l}498 \\
458\end{array}$ \\
\hline Shoulder-elbow & $\begin{array}{c}70+ \\
65-69\end{array}$ & $\begin{array}{l}371(26) \\
259(20)\end{array}$ & $\begin{array}{l}328 \\
235\end{array}$ & $\begin{array}{l}404(30) \\
264(21)\end{array}$ & $\begin{array}{l}459 \\
300\end{array}$ \\
\hline Elbow-wrist & $\begin{array}{c}70+ \\
64-69 \\
70+\end{array}$ & $\begin{array}{l}257(53) \\
226(21) \\
223(20)\end{array}$ & $\begin{array}{l}211 \\
188 \\
196\end{array}$ & $\begin{array}{l}266(20) \\
268(17) \\
263(18)\end{array}$ & $\begin{array}{l}297 \\
289 \\
288\end{array}$ \\
\hline
\end{tabular}


Table 4. Comparison of the angles between the lines combining the joints (measured in-car).

\begin{tabular}{|c|c|c|c|c|c|}
\hline \multirow[b]{2}{*}{ Measurement definitions (degrees) } & \multirow[b]{2}{*}{ Age } & \multicolumn{2}{|c|}{ Female } & \multicolumn{2}{|c|}{ Male } \\
\hline & & $\overline{\text { Mean (SD) }}$ & 5th percentile & Mean (SD) & 95th percentile \\
\hline Ankle-knee-hip & $65-69$ & $118(10)$ & 103 & $119(6)$ & 129 \\
\hline Knee-hip-shoulder & $\begin{array}{c}70+ \\
65-69\end{array}$ & $\begin{array}{c}118(11) \\
97(5)\end{array}$ & $\begin{array}{r}103 \\
90\end{array}$ & $\begin{array}{r}114(5) \\
92(5)\end{array}$ & $\begin{array}{r}129 \\
99\end{array}$ \\
\hline Hip-shoulder-elbow & $\begin{array}{c}70+ \\
65-69\end{array}$ & $\begin{array}{l}96(8) \\
37(10)\end{array}$ & $\begin{array}{l}83 \\
25\end{array}$ & $\begin{array}{l}92(5) \\
50(8)\end{array}$ & $\begin{array}{l}99 \\
61\end{array}$ \\
\hline Shoulder-elbow-wrist & $\begin{array}{c}70+ \\
65-69 \\
70+\end{array}$ & $\begin{array}{r}36(10) \\
121(18) \\
123(13)\end{array}$ & $\begin{array}{l}25 \\
97 \\
98\end{array}$ & $\begin{array}{r}43(12) \\
152(14) \\
138(20)\end{array}$ & $\begin{array}{r}59 \\
170 \\
170\end{array}$ \\
\hline
\end{tabular}

All sets of measurements are taken to assist in developing more realistic ageing ATDs and computational models. Tables 3-5 show the differences between the relatively younger and older ageing population within LU measurements.

One of the aims of this study is to find out if there is any significant differential effect of age group on the distances between joints of human body measured in car. The measured distances between joints in human body in Table 3 do not change considerably with age as most of these distances are mainly determined by the length of major bones in human body with the exception of the hipshoulder distance. No significant difference is observed between the 65-69 and 70+ age groups for the distances between the joints.

A set of four angles are given in Table 4. For all angle measurements, the differences between female age groups and 95 percentile male groups are very small. For the mean male groups, the knee-hip-shoulder angle appears to remain the same as the ageing group gets older. However, the difference of the angles between the lines connecting ankle-knee-hip joints, hip-shoulder-elbow joints and shoulder-elbow-wrist joints is significant (for all, $t$-Test $p<0.05$ ). The significant changes in the angles at the knee, shoulder and elbow joints indicate considerable changes in

Table 5. Comparison of the distances between human body and automobile features.

\begin{tabular}{|c|c|c|c|}
\hline $\begin{array}{l}\text { Measurement definitions } \\
(\mathrm{mm})\end{array}$ & Age & $\begin{array}{l}\text { Female } \\
\text { mean (SD) }\end{array}$ & $\begin{array}{c}\text { Male } \\
\text { mean (SD) }\end{array}$ \\
\hline \multirow{2}{*}{$\begin{array}{l}\text { Minimum distance between } \\
\text { the torso and steering wheel }\end{array}$} & 65-69 & $142(47)$ & $188(49)$ \\
\hline & & & 159 \\
\hline \multirow{2}{*}{$\begin{array}{l}\text { Backset: distance between } \\
\text { back of head and the head } \\
\text { restraint }\end{array}$} & 65-69 & 47 & 70 (45) \\
\hline & $70+$ & $60(41)$ & 73 (44) \\
\hline \multirow{2}{*}{$\begin{array}{l}\text { Distance between the top of } \\
\text { the head and the top of head } \\
\text { restraint }\end{array}$} & 65-69 & $3(42)$ & $61(47)$ \\
\hline & $70+$ & -8 (39) & $51(50)$ \\
\hline \multirow{2}{*}{$\begin{array}{l}\text { Distance from the front of seat } \\
\text { to the pedal }\end{array}$} & 65-69 & 411 (53) & $503(46)$ \\
\hline & $70+$ & 442 (47) & $471(46)$ \\
\hline
\end{tabular}

driving positions for the ageing male automobile drivers as they get older.

The data for the distances between the human body and automobile features are broken down by age and presented for 65-69 and 70+ age groups in Table 5. For both genders, the mean of the minimum distance between torso and the steering wheel tends to decrease with increasing age. The mean of the backset, i.e. the horizontal distance between the back of the head and the head restraint, increases with increasing age for both genders. The vertical distances between the top of head and the top of the head restraint are very similar for the two age groups for both genders; how- ever, it is worth noting that on average the 65-69 female age groups' top of the head is above the top of the head restraint whereas it is below that for the $70+$.

\section{Other features of ageing drivers}

It is reported in the literature $[9,18]$ that three key factors influence thoracic injury tolerance and thoracic stiffness associated with ageing: (1) material property changes, (2) compositional changes and (3) thoracic geometric changes. Carter and Spengler [5] claim that the elastic modulus decreases by $1.5 \%$, the yield stress by $2.2 \%$ and the ultimate strain by $5.1 \%$ per decade after the age range of 20-29. Stein and Granik [16] report a strong inverse relationship between breaking force and donor age at death after per- forming bending test on three ribs for 79 human donors aged from 27 to 83 years. Thoracic geometric changes associated with ageing include two aspects: 1) increase in kyphosis of the thoracic spine, and 2) rib cage depth increase due to associated hyperinflation with chronic obstruction pulmonary disease (COPD), which indirectly changes the rib angle. Acar and colleagues also investigate spinal posture changes by ageing at LU, through which a detailed database of ageing people spinal curvatures is created [1].

\section{Ageing occupants' comments and considerations}

In the measurement sessions, the authors had open-ended interviews with the ageing occupant volunteers regarding 
their experiences with their automobiles and any other car that they travel in. Their comments about all aspects of the driving process, self-identified requirements, dissatisfactions and their deliberations on choosing a new car are summarised below. In the semi-structured interviews, the volunteers were requested to comment on issues such as entry and egress, seat belt use, comfort and any design associated problems originating from getting older.

Apart from personal taste and ergonomics considerations, the main reasons behind ageing occupants' preferences were associated with the natural course of ageing related physical decline and medical problems. Forty-six percent of the volunteers mentioned their health conditions and current complications, which directly affected their driving experience in one way or another. The most common problems were spinal problems such as back pain, degenerated/prolapsed intervertebral discs, stiff back/lumbar spine, scoliosis and neck problems. Other joint disorders such as hip, knee or shoulder operations and/or replacements were also mentioned. In addition to these, arthritis and osteoarthritis were experienced by some of the volunteers, hindering occupants' range of motion and deteriorating their capabilities as a driver. Not so common problems included muscle problems such as Polymyalgia Rheumatica, sensitivity to light during night driving and malignant melanoma causing swollen legs.

The outcome of this study is also supported by the findings of a three-year study carried out in the USA [4] which reports age-related impairments as well as how driving behaviour may have been modified as a result of agerelated changes.

'Entry and egress' was mentioned as the major designrelated problem for ageing drivers. Fifty-one percent of the volunteers in this study either (a) experienced difficulty when they are getting in and out of their current vehicle or had specifically chosen appropriate cars for easy entry and egress - but still experience difficulty with other cars that they have to travel in. Vehicles with higher adjustable seats and relatively wide opening doors make life easier for ageing people, as they do not need to bend down to get in or find support to getout.

Twenty-five percent of the volunteers experienced seat belt problems. Around half of the complaints were due to the fact that the seat belt cut the neck even when the attachment point was at its lowest position, therefore, some of the volunteers used cushion add-on devices to the shoulder belt to avoid (still mispositioned shoulder belt) cutting the neck. Other seat belt difficulties were associated with get- ting hold of the belt tongue before fastening, uncomfortable wearing and the location of the anchorage point.

Twenty-eight percent of the volunteers were dissatisfied with their seats. Some volunteers in need of a higher seat and an upright sitting/driving posture preferred to use cushions for additional height and comfort. Other problems included the shape of the seats (causing problems when reversing), poor adjustability, short seat pans and lack of efficient lumbar and lateral support.

\section{Results and discussions}

The most commonly used ATDs are Hybrid III family members, i.e. Hybrid III 50th male, 95th male, 5th female and 10, 6, 3 years old child dummies. The features of ATDs within Hybrid III family, including head and neck, upper and lower torso, are very similar. Most of Hybrid III dummies are scaled down or up versions of Hybrid III 50th percentile male. Furthermore, dimensions of side impact and rear impact dummies such as WorldSID and BioRID-II are very similar to the dimensions of Hybrid III [6-8].

\section{Weight and stature}

Comparison between the two age groups (65+ and 18-64) in Table 1 shows that mean weights of ageing female drivers are not much different from that of the younger adults, there is $2.7 \%$ difference between the mean values. The difference in mean values for males is approximately $8.7 \%$. In terms of stature, there is not much difference between the two age groups for both female and male, yielding a maximum of $5.6 \%$ difference for the 95th percentile male, older drivers being shorter in all groups. Comparison between the average weight and stature of human subjects versus ATDs reveals that the values of ATDs are generally similar to the corresponding values of ageing subjects. As an example, the Hybrid III 5th percentile female is $150 \mathrm{~cm}$ in height, which is very similar to the height of the 5th percentile of ageing female driver, $149 \mathrm{~cm}$, in this study. The largest difference is observed in the weight of male drivers. The mean weight of the ageing male drivers is $10 \%$ and $12.2 \%$ greater than those of ATDs for 50th and 95th percentile groups, respectively. The comparisons between the weight and stature of the ageing drivers and the corresponding values of respective ATDs are shown in Figures 8 and 9, respectively.

\section{Sitting height}

Sitting height of ageing drivers is significantly lower than those of the younger adults for all groups, that is $10.2 \%$ for the 5 th percentile females and $10.4 \%$ for the 95 th percentile males (see Table 1 ). The sitting height of $70+$ ageing drivers is even lower than those of the 65-69 group (see Table 2). The sitting height of ageing driver is also much lowerthan the corresponding value of ATDs, which is particularly observed for the female drivers. The sitting height of 5th per- centile of ageing female is $9.7 \%$ lower than that of Hybrid III 5th percentile female and equivalent to the sitting height of Hybrid III 10 years old child ATD. 


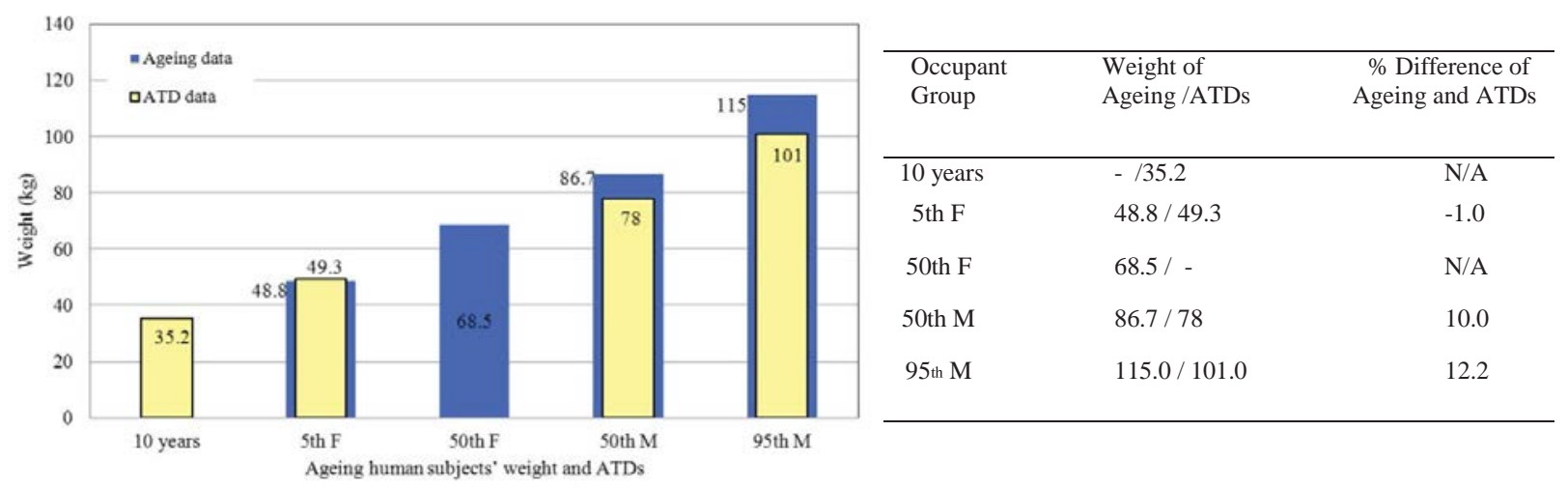

Figure 8. Comparison of weight of ageing drivers and ATDs.

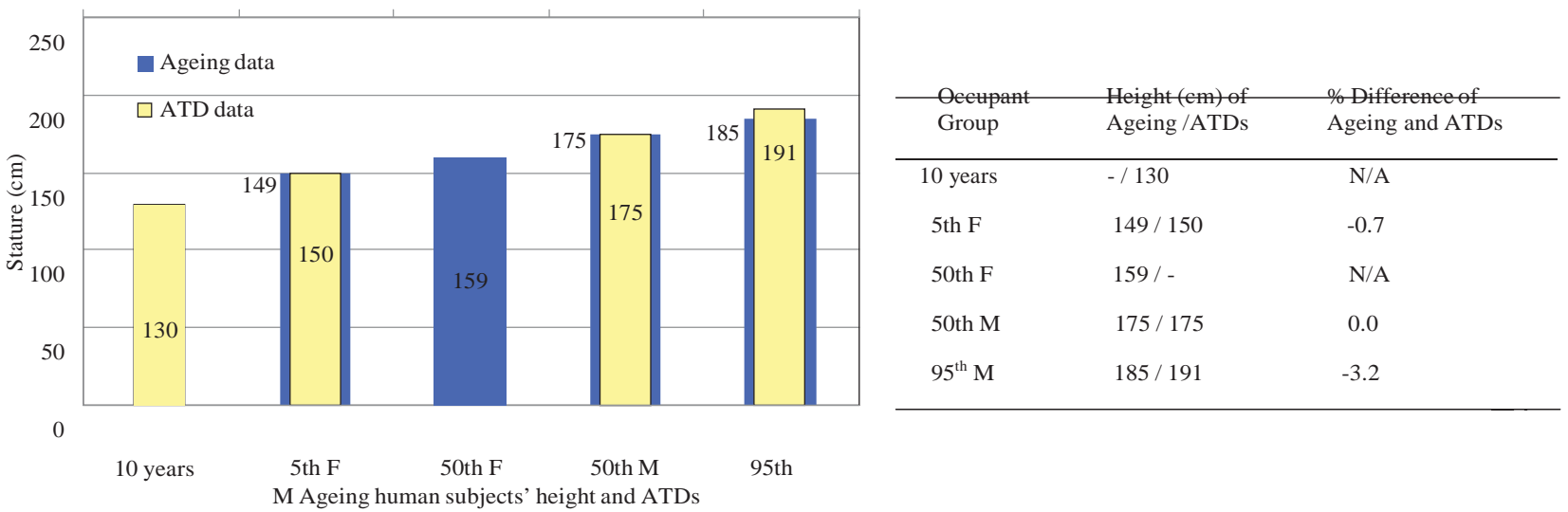

Figure 9. Comparison of stature of ageing drivers and ATDs.

Similarly, the sitting height in 50th percentile of ageing female is equivalent to the sitting height of Hybrid III 5th percentile female ATD. Furthermore, sitting height of the 95th percentile male is closer to 50th percentile male ATD than 95th percentile male ATD. Comparison of sitting heights between ageing drivers and ATDs can be seen in Figure 10.

\section{Distance from torso to steering wheel and backset}

This study shows that the older the driver the closer they are sitting to the steering wheel (see Table 5), which might be the one of causes of high ratio of chest injuries for ageing drivers. Backset, the horizontal distance between the head restraint and back of head, for ageing drivers generally appears to be high (see Table 5), which potentially poses a whiplash injury risk.

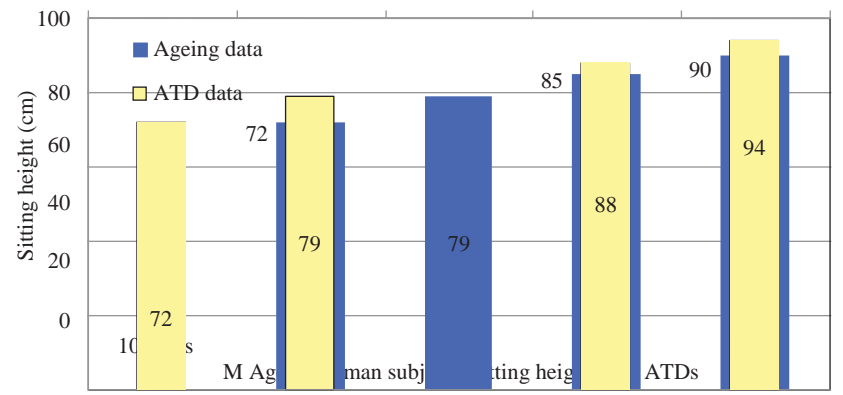

\begin{tabular}{ccc}
\hline $\begin{array}{l}\text { Occupant } \\
\text { Group }\end{array}$ & $\begin{array}{l}\text { Sitting height }(\mathrm{cm}) \text { of } \\
\text { Ageing /ATDs }\end{array}$ & $\begin{array}{c}\text { \% Difference } \\
\text { Ageing and ATDs }\end{array}$ \\
\hline 10 years & $-/ 72$ & N/A \\
5th F & $72 / 79$ & -9.7 \\
50th F & $79 /-$ & N/A \\
50th M & $85 / 88$ & -3.5 \\
95 M & $90 / 94$ & -4.4 \\
\hline
\end{tabular}

Figure 10. Comparison of sitting height of ageing drivers and ATDs. 


\section{Specifications}

According to the features of the ageing drivers identified in this study, the ATDs representing the ageing driver are required:

- to have more representative weight and stature than the currently available ATDs,

- to have smaller sitting heights than those of the currently available ATDs for each group - for example, currently in terms of sitting height, a 10 years old child ATD represents the small ageing female car occupants better than the 5th percentile female ATD,

- to be capable of testing the crashworthiness caused by the 'out of position' - due to the factors such as sitting height and spinal posture, especially the ageing females are sitting close to the steering wheel and usually out ofposition,

- to be able to assess the injuries caused by the interaction between human body with steering wheel and airbag due to the proximity between torso and steering wheel and other automobile interior components,

- to be able to reflect the geometric changes associated with ageing such as kyphosis and rib angle increase, to be manufactured with adequate materials representing the changes in the biomechanical properties such as the bone density and stiffness of ageing subjects,

- to be suitable for various different scenarios and can provide information after side and oblique impacts as well as frontal collisions.

\section{Conclusions}

In this study, the features of ageing drivers are identified through anthropometric and in-car measurements for 100 volunteers aged 65 years old and above and the results are compared with younger adults. Comparing the features of ageing drivers with the characteristics of current ATDs indicates that the current ATDs could not incorporate all features of ageing drivers. The requirements of future ATDs representing the features of ageing drivers are highlighted such as adequate sitting height, abdominal depth and spinal posture.

Research on ATD Injury Assessment Reference Values or seating/positioning procedures specifically for ageing population is scarce. Based on the findings of the research reported in this article, modification of existing seating and positioning procedures for the existing ATDs would not be an adequate representation of the ageing occupant. Authors believe that existing ATD Injury Assessment Reference Values and seating procedures need to be adjusted for ageing anthropometry and driving postures, and tests should be carried out with ATDs representing ageing occupants.
High ratio of fatality per mile driven for ageing drivers is a serious problem in automotive safety and injury prevention field. Therefore, the features of ageing drivers identified in this study and the corresponding requirements for new ATDs representing ageing drivers are believed to be significant contributions for the automotive designers and safety engineers towards making the automobiles safer for everybody including the physically and mentally healthy ageing people.

\section{Acknowledgements}

The authors gratefully acknowledge funding support from Engineering and Physical Sciences Research Council and Loughborough University Innovative Manufacturing and Construction Research Centre. The authors also thank the volunteers who participated in the measurement sessions of this study.

\section{Notation}

ATD Anthropomorphic Test Device

$n \quad$ population size

$P \quad$ measured parameter

$p \quad$ probability associated with Student's $t$-test

\section{References}

[1] B.S. Acar, M. Acar, and B.B. Kentel, Investigating the full spinal curvature changes in the ageing population, Proceedings of the 9th International Symposium on Computer Methods in Biomechanics and Biomedical Engineering, Valencia, Spain, 2010.

[2] L. Bailey, Ageing Americans: stranded without options, Data collected and distributed by NHTSA in Fatality Analysis Reporting System (FARS), original data analysis by Surface Transportation Policy Project, Washington, DC, 2004.

[3] L. Bailey, Ageing Americans: stranded without options, Data collected and distributed by US Department of Transportation in National Household Travel Survey (NHTS) in 2001, original data analysis by Surface Transportation Pol- icy Project, Washington, DC, 2004.

[4] K.A. Braitman and A.F. Williams, Changes in selfregulatory driving among older drivers over time, Traffic Injury Prev. 12(6) (2011), pp. 568-575.

[5] D.A. Carter and D.M. Spengler, Mechanical properties and compositions of cortical bone, Clin. Orthop. Relat. Res. 135 (1978), pp. 192-217.

[6] R.P. Daniel, A. Irwin, J. Athey, J. Balser, P.Eichbrecht, R.W. Hultman, S. Kirkish, A. Kneisly, H. Mertz, G. Nusholtz, S. Rouhana, R. Scherer, M. Salloum, and J. Smrcka, Technical specifications of the SID-IIs dummy, Proceedings of the 39th Stapp Car Crash Conference, 1995, San Diego, CA, USA, pp. 359-388.

[7] V.Esat, J. Feng, and B.S. Acar, Features of ageing female car drivers for computational modelling, Proceedings of the 9th International Symposium on Computer Methods in Biomechanics and Biomedical Engineering, Valencia, Spain, 2010, p. 9.

[8] J.R. Kelly, BioRID-IIc Rear Impact Crash Test Dummy, BioRID II User's Guide, Denton ATD, Inc., Huron, OH, USA, 2002. 
[9] R. Kent, S.-H. Lee, and K. Darvish, Structure and material changes in the ageing thorax and their role in crash protection for older occupants, Stapp Car Crash J. 49 (2005), pp. 231-249.

[10] D.R. Mayhew, H.M. Simpson, and S.A. Ferguson, Collision involving senior drivers: High-risk conditions and locations, Traffic Injury Prev. 7(2) (2006), pp. 117-124.

[11] S. Moss, Z. Wang, M. Salloum, M. Reed, M. van Ratingen, D. Cesari, R. Scherer, T. Uchimura, and M. Beusenberg, Anthropometry for WorldSID: A world-harmonized midsize male side impact crash dummy, Tech. Documents No. 200001-2202, SAE International, Warrendale, PA, USA, 2000.

[12] News and Releases, WorldSID, Available at http://www. worldsid.org/News/2004-June_Rev1_2000_pg3.pdf.

[13] OECD, Ageing and Transport: Mobility Needs and Safety Issues. OECD Scientific Expert Group, Paris, 2001.
[14] Office for National Statistics, 2008-based National Popula tion Projections (2009), Available at http://www.statistics. gov.uk/downloads/theme_population/NPP2008/NatPopProj 2008.pdf.

[15] L. Peebles and B. Norris, Adultdata: The Handbook of Adult Anthropometric and Strength Measurements - Data for Design Safety, Department of Trade and Industry, UK, 1998.

[16] I.D. Stein and G. Granik, Rib structure and bending strength: An autopsy study, Calcified Tissue Int. 20(1) (1976), pp. 61-73.

[17] R. Welsh, A. Morris, A. Hassan, and J. Charlton, Crash characteristics and injury outcomes for older passenger car occupants, Transp. Res. F 9(5) (2006), pp. 322-334.

[18] Q. Zhou, S. Rouhana, and J. Melvin, Age effects on thoracic injury tolerance, Proceedings of the 40th Stapp Car Crash Conference, 1996, Albuquarque, NM, USA. 